\title{
A QUALITATIVE STUDY OF STUDENTS' PERCEPTION ON MULTICULTURAL COMPETENCE OF ACADEMIC TEACHERS IN INDIA
}

\author{
Kamila Ludwikowska
}

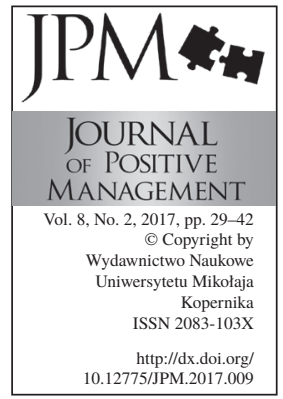

Wroclaw University of Science and Technology, Wroclaw, Poland

e-mail: kamila.ludwikowska@pwr.edu.pl

\begin{abstract}
Purpose: This study aims to identify multicultural competences (behaviours, knowledge and attitudes) specific for teaching culturally diverse students belonging to different nationalities and ethnicities, discuss their essence and importance.
\end{abstract}

Methodology/approach: To explore understanding of multicultural competences a case study approach was applied. Qualitative research was based on the students' feedback survey containing open ended questions.

Findings: The results of the study allow to answer the research question which multicultural competences are key for teachers. From a students' perspective teachers should be aware of special needs of individuals from different cultural backgrounds. Therefore, they should apply this knowledge to specific teaching strategies and interpersonal cues to create a supportive classroom atmosphere and to cater the needs of diverse students.

Implications: The current focus in the well-established tradition of teaching and learning in India is not only on the development of professional competences, achieving higher levels of commitment and motivation, but also building multicultural competences. Today's classrooms require teachers to teach students with different cultures, languages, abilities and other characteristics. The framework of developing core multicultural competences should be built based on perspective of different groups of stakeholders.

Originality/value of the paper: The results have special added value in defining key multicultural competences of academic teachers and building framework of teaching competences in global context.

Keywords: multicultural competence, multicultural education, cultural diversity, higher education Paper type: Case study

\section{Introduction}

Education system of India has a well-established tradition of teaching and learning. The tradition of teaching and teachers in the ancient Indian scriptures declared four obligations for every human being: towards God, parents, teachers and human 
A QUALITATIVE STUDY OF STUDENTS' PERCEPTION

Kamila Ludwikowska society. The system, known as the Gurukula system, emphasized a reverence to the "Guru" (the revered teacher) and was characterized by a sense of total respect from the learner to the Guru and the total responsibility of the Guru for the wholesome development of the learner (Rajput and Walia, 2001). In ancient India, the Guru was the guide, leader, and creator of knowledge as well as the disseminator of knowledge. This approach greatly influenced Indian philosophy and tradition regarding teaching and learning and put the Guru on the highest pedestal.

This great tradition has continued up to present times and has major implications for how education and teachers are regarded, and for teachers' roles in Indian Society.

The Indian education system in the post-independence period attempted to align itself in accordance with guidelines contained in the Constitution of India, with further major policy formulations (Government of India, 1950). In 1956, Parliament established the University Grants Commission (UGC) as a national regulator of standards in higher education. Among many activities, the UGC was empowered to define teachers' qualifications through maintaining standards of teaching, examination and research (Carnoy and Dossani, 2013). Since 1984 and continues to the present educational priorities started changing due to the influence of stakeholder groups and new forces such as globalization (Carnoy and Dossani, 2013).

Nowa days, in globalized world the relationship between a student and a teacher has created a new meaning. The role of a teacher has changed from a knowledge transmitter to a friend, the relationship has evolved into an open and interactive association. Students don't want to act as consumers of facts, they strive to be creators of knowledge. It leads to a new series of expectation from students. Today the respect for a teacher doesn't come just on the basis of a teacher - student relationship as in the old times - it comes from the expectation fulfilment for students. Nowadays, the teachers should continually improve and adapt themselves according to the students. The tasks assigned to teachers have gradually expanded and become more demanding.

We live in a world that is full of people of different skin colours, different religions and different beliefs. All around the world mobility in higher education is becoming increasingly important. The mobility has created classrooms with students of different backgrounds thus it become essential for teachers to understand the changing demographics and experience of students.

Therefore, one of the growing expectations towards teachers is to be competent to manage cultural diversity in the classroom and to be capable to teach young people from different cultural backgrounds as well as to create self-awareness of global world. Thus, this study aims to identify multicultural competences in terms of behaviours, knowledge and attitudes, specific for teaching culturally diverse students, discuss their essence and importance. 


\section{Background and literature review}

Education is an important instrument in building human capital, knowledge and competence leading to human resource development and economic growth. All countries that want to have an efficient economy must invest in knowledge, skills and competences of their members. Education is the key to a process of development, it needs to be planned and executed with great sensitivity. Qualified and experienced employees as well as scientific personnel is viewed as knowledge carriers.

Currently, education is under the influence of globalisation with multidimensional impact on the system of education. Globalization is affecting not only the economy, culture, information, internationalization of relations and is increasing mobility of individuals but also has multi-dimensional impact on education. The era of globalization has implications for knowledge, education and learning. Revolution in the communication media, the automation of daily life and the workplace with Information Communication Technology (ICT) all presents challenges and opportunities to the system of education. In the last decades, the nature of teachers' work and knowledge has undergone enormous changes under the influence of globalization processes.

India, seventh-largest country by area, country with 29 states and 7 union territories is the fastest-growing major economies in the world with significant focus on higher education system. The issue of education has become increasingly important, since unemployment rates in India are still very high and the percentage of educated people who are unemployed is increasing. Education needs to participate in preparing young persons for the world of work.

The opening up of Indian economy, access to new technologies facilitated by globalization has helped to expand the scale and modes of internationalization (Panikkar and Nair, 2012). Internationalization is not a totally unknown phenomenon in higher education in India. For many decades students gone abroad for higher studies and professionals have gone out to teach or do research.

What is new, however, is the much larger scale of such activities and inputs today, and the adoption of new modes of delivery of higher education. For example, more popular is becoming distance learning, international educationrelated internships and training experiences, exchange programmes, joint programmes. In this context, people become more aware of other cultures and the benefits arising from studying abroad.

The number of Indian students going abroad to study is growing faster than ever before. The number of students from India going overseas to study in 2010 was over 200.000 (Project Atlas, 2013), while in 2015 the international students from India crossed the 350.000 (Indian Students Mobility Report, 2016). Indian student growth overseas is still powered by a lack of places in good Indian
A QUALITATIVE STUDY OF STUDENTS' PERCEPTION

Kamila Ludwikowska 
A QUALITATIVE

STUDY OF STUDENTS'

PERCEPTION

Kamila Ludwikowska institutions, even for the best students with highest marks who cannot assume they will get into the Indian institution of their choice.

The internationalization of universities, the movements across borders by students has a huge impact on university systems. This means that there are number of challenges that teachers need to face with to prepare students for growing need of the global exposure. Global mobility means that culturally homogenous classrooms are now increasingly rare.

There is an intense mix of people and nations today in the world. India, apart from being fastest growing economy, is also the second-most populous country with over 1.2 billion people, pluralistic, multilingual with 122 major languages and multi-ethnic society which means that it's country culturally diversified itself. This cultural diversity is increasing and can be observed also in the classrooms. The fact that students have similar cultural heritage does not mean that they are all the same. Every student is an individual with unique characteristics that include strengths and challenges. All students should have an opportunity to learn regardless of background or ethnic identity and teachers need to be prepared to work effectively with them. There is an expectation that teachers need to raise personal awareness about cultural individual differences, and how these differences enhance or hinder the ways students and teachers interact with each other. Specifically, teachers need to engage in self-reflections about their own biases and develop respect for the differences, and the willingness to approach teaching from a multicultural perspective.

Many teachers face challenges to respond appropriately to the cultural diversity they are likely to encounter in the classroom (Jones, 2004). As a result, there is growing pressure and focus on teachers to provide diversity experiences for their students and understanding similarities and differences between cultures. Hence, they need to develop multicultural competences to understand how to work with diverse students represented in the classroom.

In the literature search on multicultural competences that term is used together with cultural diversity and multicultural education which refers to a specific model of educational provision.

Multicultural education is an educational reform movement that provides equal opportunities for all students, including those from different races, ethnic groups, social classes. There is a need to create an environment that is equitable and try to search for a balance of views and present them as fairly, as possible (Banks, 2016). In addition, multicultural education has several goals that it works towards, from individuals gaining deeper insight into their own cultures to helping individuals from diverse backgrounds to function effectively within cultural, regional, national and global communities (Banks, 2016). Furthermore, there are clear benchmarks that can be used to assess and maintain an effective multicultural environment - these include policy statements, staff attitudes, 
curriculum monitoring, teaching strategies, teaching materials and parents participation (Banks, 2010).

Bennett (2007) holds a view that multicultural education is an approach to teaching and learning that has foundation in democratic values and beliefs, it should be perceived as a commitment to affirm and appreciate cultural diversity. Multicultural education means acquiring increased awareness of cultural context (worldview), developing ability to interact across cultures. Educational excellence can be attained through a unique perspective of an individual and understanding culturally different students. This can be achieved through movement towards equity, curriculum reform, multicultural competence, and teaching toward reform. Bennett's (2007) part of the definition of multicultural competence also indicates „multicultural sensitivity” as a perception of cultural differences.

Banks (2010) posited that to implement multicultural education there is a need to think of a school as a system in which major variables are interrelated. Thus, Banks (2010) identified dimensions of multicultural education: content integration, knowledge construction process, prejudice reduction, equity pedagogy and empowering school culture and social structure. Reform any one of the variables is necessary, but not sufficient. Each variable underlines the role of teacher and necessity to help them to gain knowledge about diverse groups, attitudes, values of students.

Different definitions of multicultural education consider common concepts, such as tolerating cultural differences, reflective teaching, analysing different views and opinions. It is an intentional process of acquiring knowledge, skills and abilities and building multicultural awareness in multicultural environment. The basic objective of multicultural education is to increase academic achievement of the students, prevent prejudices about cultural differences through increasing multicultural competences of teachers.

However, in the literature there is a confusion about overall aims of the multicultural education, that there is more than one model of such education (Iwrin, 1989) and that the term has a variety of meanings.

Multicultural education is important not only because we learn to respect differences, but also in the realization that teaching should be a process through which we are constantly reflecting and changing ideas to create effective classrooms for all students. Examining the past ideas and understanding differences have an impact on teacher's pedagogy.

The focus of this article is to explore multicultural competences for teachers, their preparation for cultural diversity and that cultural diversity is not synonym with multicultural education. To clarify the meaning of cultural diversity used in this study, it is necessary to explain how the notion of culture and diversity is conceptualised.
A QUALITATIVE STUDY OF STUDENTS' PERCEPTION

Kamila Ludwikowska 
A QUALITATIVE STUDY OF STUDENTS' PERCEPTION

Kamila Ludwikowska
Culture characterises group of people with different language, religion, habits, dress, custom, traditions, ways of thinking and behaving. The essence of the culture is how members of the group interpret, use and perceive artefacts, tools or other cultural elements. Values, symbols, interpretations, and perspectives distinguish one people from another in societies (Banks, 2010).

Diversity is defined in terms of nationality, as well as ethnic, racial and religious differences between people. Gorski (1997) reports that in the classroom diversity refers to three components: curriculum, teacher and student. First component, curriculum, should include contribution from different ethnic groups, provide opportunity for students to discuss racial and ethnicity related questions, share everyday life examples and encourage to interact with students from different backgrounds. Second component, teacher, is perceived as a leader of cultural diversity and multicultural education. Teachers must assess own prejudice values, encourage groups to openly discuss and debate multicultural issues, offer the best learning environment and continuously develop oneself. Thirdly, students need to be encouraged to share own stories and be open to hear the stories of others. For this purpose, teacher must care about non-judgemental atmosphere in the classroom, where student feel free to discuss openly own views, present own values and beliefs (Gorski, 1997).

Hence, cultural diversity is a form of appreciating the differences in individuals and indicates existence of a variety of cultural or ethnic groups within society, like gender, age, sex, ethnicity, social status. Cultural diversity increased complexity of teacher's work. All teachers, regardless of their location, need to be culturally responsive practitioners who must be able to work with diverse students. A culturally responsive teacher respects and understands students' values, knowledge, practices, expectations, promotes social justice through naming and critiquing discourses of inequality within and beyond the classroom (Santoro et al., 2015). There is a need to prepare culturally responsive teachers with the ability to communicate with students from diverse backgrounds, as well as students to communicate among diversified group in the classroom.

At this point the literature review focuses on a discussion of the multicultural competences for teachers to be adequately prepared to teach effectively in culturally diverse environments. The capability to teach effectively and culturally responsively is framed in terms of teacher multicultural competence.

Multicultural competence has various definitions. Some researchers describe capability to teach in culturally diverse environment in terms of developing sociocultural competences (Moll and Arnot-Hopffer, 2005). Sociocultural competence is defined in terms of three key skills: firstly, that teachers develop an awareness of their own cultural biases and prejudices about human behaviour; secondly, that they have knowledge of the sociocultural backgrounds of their learners; and third that they are able to implement culturally responsive strategies 
in the classroom (Moll and Arnot-Hopffer, 2005). Sociocultural competence provides the opportunity to orient in the new sociocultural environment, interact adequate in everyday life situations, maintain social contacts and describes readiness of a teacher to work in a multicultural environment. It also allows a teacher to avoid conflicts with students and their parents on intercultural ground (Stakhiv and Boiko, 2017). Sociocultural competence is also defined as the ability to apply a set of multicultural knowledge, skills and qualities in the process of intercultural communication in the specific conditions of life and tolerance towards people of other nationalities (Stakhiv and Boiko, 2017).

Many researchers that studied this issue describe multicultural competence in terms of multicultural counseling competences (MCC) of school counselors.

In some countries, school counseling is provided by school counseling specialists (for example, China, Finland, Israel, Malta, Nigeria, Romania, Taiwan, Turkey, United States). In other cases, school counseling is provided by classroom teachers who have such duties added to their teaching load or teach only a limited load that also includes school counseling activities (besides India also Japan, Mexico, South Korea) (Harris, 2013). Multicultural counselling competences have been conceptualized as the awareness of one's stereotypes and biases, knowledge of one's own and other's worldview, and skills that counselors require to work effectively with diverse individuals (Guzman et al., 2013). Currently, four major self-report MCC scales are distinguished as most relevant to measure multicultural competence: Cross-Cultural Counseling Inventory - Revised (CCCI-R), Multicultural Awareness/Knowledge/Skills Survey (MAKSS), Multicultural Counseling Inventory (MCI), and the Multicultural Counseling Knowledge and Awareness (MCKAS) that has received increasing utilization among researchers in counseling psychology and other counseling fields ( $\mathrm{Lu}, 2017)$. it has been found that each instrument followed the model of multicultural competency developed by Derald Wing Sue and team (Dunn et al., 2006).

The Cross-Cultural Counseling Competency Model, published by Sue et al. in the 1982, had the biggest influence on the creation of the model of multicultural competency. It defined 11 competences in the field of mental health counseling and psychotherapy within three components: beliefs/attitudes and cultural awareness, cultural knowledge and cultural skills. Attitudes/beliefs are conceptualized by Sue et al. (1982) as social conditioning that requires self-examination of attitudes and feelings associated with cultural differences. The second component, cultural knowledge allows to understand and share the worldview through empathy. Cultural skills emphasise that counselors need to work continually to develop their attributes of cultural competence hence they can provide effective counseling interventions.

The original tripartite model of MCC became the foundation for many definitions of multicultural competence (Hladik and Jadama, 2016).
A QUALITATIVE STUDY OF STUDENTS' PERCEPTION

Kamila Ludwikowska 
A QUALITATIVE STUDY OF STUDENTS' PERCEPTION

Kamila Ludwikowska
Many definitions of multicultural competence refer to efficiency in communication between cultures. It is conceptualized as the ability to communicate effectively in different situations, based on intercultural knowledge, skills and attitudes (Deardorff, 2006). (Deardorff and many other authors use the term ,intercultural". In order to unify concepts in this article the term "multicultural" is used, as both are perceived to be identical). In this context, multicultural competence plays significant role in the communication process between representatives of different cultures.

The Model of Intercultural Competence, developed by Deardorff (2006), presents intercultural competences as a process that begins with attitudes of valuing other cultures, openness to intercultural learning and people from other cultures, and tolerating ambiguity and uncertainty as fundamental to achieve the desired internal and external outcomes. In terms of knowledge cultural selfawareness is stressed, as well as skills, such as listening, observing, analysing, evaluating and relating (Deardorff, 2006).

A search of literature shows that there are number of multicultural competency models. Most studies identified multicultural competences in terms of awareness of one's and other's cultural differences, experiences, stereotypes and biases, respecting other's perspective and ideas, having knowledge of the diverse backgrounds of learners and skills to work effectively in multicultural environment. In majority, to measure multicultural competences researchers used different instruments where variables have already been named. Thus, there is a gap in qualitative approach of identifying multicultural competences of teachers by different groups of stakeholders, such as employers, students.

This research, therefore, aims to determine multicultural competences for teachers from students' perspective.

\section{Methodology of the research}

There are many ways to evaluate teaching and learning in higher education and, collecting students' feedback is one of the strategies. According to Rowley (2003) one of the main reason to collect students' feedback is to allow them to share their comments, to encourage students' reflection on learning, to allow students to express their level of satisfaction, to give them a sense of importance of their perspective as well as improve quality of teaching.

This qualitative investigation utilized a case study approach to examine the participants' worldviews on multicultural competences. To facilitate understanding of multicultural competences among students the feedback survey was used.

Qualitative research was applied as a method of an in-depth study to ensure insights into the problem and help to develop ideas or hypotheses for potential further quantitative research. 
Based upon a review of the literature and in consultation with experts in the field of education at the university nine open-ended questions were developed:

1) How would you describe academic teacher who is supporting for students?

2) What academic teacher should do to create learning environment?

3) How would you describe modern teaching style?

4) Which leadership skills are important for academic teacher?

5) Which multicultural competences are important for academic teacher?

6) Which teaching competences would be important in the nearest future?

7) Which teaching methods would you like to experience in the classroom?

8) Which personality traits are important for academic teacher?

9) What are the most demotivating behaviours of academic teacher that you have experienced?

The underlying research is a pilot study and a preliminary step to a large-scale research in terms of developing the model of teaching competences.

In the current paper the following research question was addressed:

1. Which multicultural competences are important for academic teacher?

Following approval from the university authorities, an e-mail invitation has been sent to 218 students from one of the universities in India. Respondents have been informed about the objective of the study and they were ensured the anonymity. The feedback has been received from 85 students (39\%), 36\% studied at undergraduate level, $33 \%$ postgraduate and $31 \%$ attended pre-PhD course. The group was almost homogeneous according to the gender, $94 \%$ was represented by female. It might be explained by the fact that the survey has been sent to students from the Psychology Department which consists mostly of women.

Out of 85 surveys 7 were rejected because of unreliable answers on the question on multicultural competences for teachers (such us "I don't understand question", "I don't know" or lack of answer). For further analysis on multicultural competences 78 (36\%) surveys were approved. Data sources included statements which multicultural competences are important for teacher. Grounded theory approach guided the data analysis to identify emerging themes. Data analysis procedure involved highlighting phrases that were descriptive of participants' perspective. Key phrases were highlighted, categorized and organized into statements. Verification of the results was attained through sharing the findings with the participants. The extracted multicultural competences were identified followed be the supportive literature.

\section{Research results}

Based on the literature search and data analysis, key phrases from the research question "Which multicultural competences are important for academic teachers?" were highlighted and organized in themes making a total of five competences which have been named as follows:
A QUALITATIVE STUDY OF STUDENTS' PERCEPTION

Kamila Ludwikowska 
A QUALITATIVE

STUDY OF STUDENTS'

PERCEPTION

Kamila Ludwikowska
1) Understanding and respecting cultural diversity.

2) Awareness of own biases and prejudices.

3) Awareness of other cultures.

4) Openness and acceptance of different ideas and views.

5) Adjusting teaching style to students from different backgrounds.

The components under first competence, named "Understanding and respecting cultural diversity", are related to understanding that people have different backgrounds, lifestyle, traditions or customs. Therefore, according to students' perspective teacher should shape attitudes and behavior of students in the classroom through understanding that individuals belong to different nationalities and ethnicities and have varied cultural backgrounds.

The term "biases" used in the second competence "Awareness of own biases and prejudices", is a kind of inclination or prejudice against person or group, especially in a way considered to be unfair. Students reported that it is important that teacher is aware own cultural biases and values, this helps to see students' worldview, use different cultural examples.

The competence named "Awareness of other cultures" refers to comprehensive knowledge and broad multicultural perspective which facilitates the incorporation other cultural contexts in teaching. Teacher should be aware of differences between cultures, traditions, customs and be able to incorporate to learning practice. Teacher also should be sensitive to specific culture and background of problems of the learner, then will be able to initiate a dialogue with members of different cultures. To begin that process, it is required to reflect own identity development and consider how teachers' perspective could influence their teaching and interaction with students from different backgrounds.

Students referred also that teacher should promote knowledge about other cultures among university society. This is relevant to some authors' implications that the positive promotion of cultural diversity should guarantee social cohesion, solidarity and, response to the need to improve educational and social coexistence (Vélez and Olivencia, 2017).

According to the Big Five personality inventory, one of the most widely applied models of personality, openness is commonly associated with being imaginative, cultured, curious, original, broad-minded, intelligent, and artistically sensitive (Murray and Mount, 1991). From the students' viewpoint, the next multicultural competence named "Openness and acceptance of different ideas and views" refers to understanding and accepting ideas, ideologies others than own. Teacher needs to listen and be open to any sort of ideas that comes from the class. To broaden openness teacher should take every opportunity to gain cultural competence.

The last competence listed as "Adjusting teaching style to students from different backgrounds" refers to the knowledge provider. In order to help 
students to learn effectively teacher needs to understand and adapt teaching style, appropriately develop instructions, techniques, evaluation and material for students. In conducted studies respondents claimed that to bring together students of all cultures, encourage them to speak about their culture and use them as examples in their studies, be interactive with them, teacher should use such techniques which can be applied to students coming from different cultural background. This enable teacher to connect the learning experiences with facts and stories of individual cultures of the students. Teacher should be also understanding, empathetic, has ability to listen and communicate effectively, therefore will be able to give individual importance to each student.

The results of the study reflect that teachers play dominant role in creating supportive learning environment for culturally diverse students.

\section{Conclusions and further research}

Multicultural competence often determines teachers' effectiveness in culturally diverse classroom and is linked to increased academic performance of students, self- esteem, and overall well-being.

This study aimed to identify multicultural competence (behaviours, knowledge and attitudes) specific for teaching students belonging to different nationalities and ethnicities, discuss their essence and importance. This analysis of the case study allows to identify the key multicultural competences for the teacher. It is worth noticing that respondents were aware about their expectations according to the scope of multicultural competence for a teacher. They proved that they understand the importance and benefits of this multicultural experience.

In addition, literature studies have confirmed importance of selected multicultural competences. Most studies identified multicultural competences in terms of awareness of one's and other's cultural differences, experiences, stereotypes and biases, respecting other's perspective and ideas, having knowledge of the diverse backgrounds of learners and skills to work effectively in multicultural environment.

Sadker et al. (2008) posited that many teachers hold various misconceptions, false beliefs, stereotypes and erroneous attitudes about minorities. Teachers' beliefs about how students from different backgrounds learn and the expectations that they have for different groups may influence the way they conduct their lessons. When teachers ignore or reject different cultural expressions of development that are normal and adequate and on which school skills and knowledge can be built, conflicts can occur which may lead to student failure (Keengwe, 2010).

Therefore, to enhance development of multicultural competences, the universities are required to provide cross-cultural (cultural diversity) trainings for teachers to enhance their experiences interacting with students from other cultures. Blaskova et al. (2015) reported that teachers should participate in the foreign
A QUALITATIVE STUDY OF STUDENTS' PERCEPTION

Kamila Ludwikowska 
A QUALITATIVE STUDY OF STUDENTS' PERCEPTION

Kamila Ludwikowska academic internships and scholarships. This indicates a practical approach to develop multicultural competences that can be obtained thorough global exposure. To achieve this, it's recommended that teachers experience different cultures, apply new knowledge and provide necessary support for cultural diversity in the classroom. The international environment can strongly accelerate the training progress and create new multicultural knowledge.

The presented study is a pilot research and it requires further research. That is why presented research approach is not free from limitations. Few limitations of the study are evident. The first limitation is the nature of the research. Only a small selection of participants of one gender volunteered to participate in the study. Additionally, it is narrowed only to students' perspective. Thus, the findings of the study are specific to the group of students and their feedback and cannot be generalized on a larger scale.

Future research should be focused on developing tool to measure multicultural competence for teachers in academic environment. The emphasis should be put on developing behaviorally rating scales for self-evaluation of multicultural competencies as well as evaluation by different groups of stakeholders that influence higher education, such as employers.

This research is important and original because of the application of the case study as a method to emerge the key multicultural competences from the perspective of the other than teachers' stakeholders. Such approach allows to see different perspective on the multicultural competences. Universities can support teachers to improve their cultural awareness by implementing cross-cultural trainings. Multicultural trainings for teachers can help to increase their knowledge and skills in order to become effective educators of culturally diverse students.

\section{References}

Ameny-Dixon, G. (2004), "Why Multicultural Education Is More Important In Higher Education Now Than Ever: A Global Perspective", International Journal of Scholarly Academic International Diversity, Vol. 6 No. 4, pp. 1-12.

Banks, J.A. (2010), Multicultural education. Issues and perspectives, Wiley, USA.

Banks, J.A. (2016), Cultural diversity and education: Foundations, curriculum and teaching, Routledge, New York.

Bennett, C.I. (2007), Comprehensive multicultural education (6 $6^{\text {th }}$ ed.), Pearson, Boston.

Blaskova, M., Blasko, R., Matuska, E., Rosak-Szyrocka, J. (2015), "Development of Key Competences of University Teachers and Managers", Procedia - Social and Behavioral Sciences, Vol. 182, pp. 187-196. DOI: 10.1016/j.sbspro.2015.04.755

Carnoy, M., Dossani, R. (2013), "Goals and governance of higher education in India", Higher Education, No. 65, pp. 595-612.

Dunn, T., Smith, T., Montoya, J. (2006), "Multicultural Competency Instrumentation: A Review and Analysis of Reliability Generalization", Journal of Counseling and Development, Vol. 84 No. 4, pp. 471-482. DOI: 10.1002/j.1556-6678.2006.tb00431.x 
Gorski, P. (1997), Initial thoughts on multicultural education-multicultural pavilion, MacMillian Publishing Company, New York.

Government of India (1950), Constitution of India, New Delhi.

Guzman, M.R., Calfa, N.A., Kerne, V., McCarthy, Ch. (2013), "Examination of Multicul-

A QUALITATIVE STUDY OF STUDENTS' PERCEPTION

Kamila Ludwikowska tural Counseling Competencies in School Counselors", Journal of School Counseling, Vol. 11 No. 7, pp. 1-27.

Harris, B. (2013), "International school-based counselling”, available at: https://www. researchgate.net/publication/259077683_School-based_counselling_internationa 1ly_a_scoping_review (accessed 20 June 2017).

Deardorff, D.K. (2009), "Implementing intercultural competence assessment", in: Deardorff, D.K. (Ed.), The SAGE Handbook of intercultural competence, SAGE Publication, Thousand Oaks, pp. 471-491.

Jones, H. (2004), "A research-based approach on teaching to diversity", Journal of Instructional Psychology, No. 31, pp. 12-19.

Lu, J. (2017), "Multicultural Counseling Knowledge and Awareness Scale: Re-Exploration and Refinement", International Journal for the Advancement of Counselling, Vol. 39 No. 1, pp. 14-27.

Hladik, J., Jadama, L.M. (2016), "Multicultural Competence of Helping Profession Students: Cross-cultural Comparison between Europe and Africa", Procedia - Social and Behavioral Sciences, Vol. 217, pp. 669-678. DOI: 10.1016/j.sbspro.2016.02.117

Keengwe, J. (2010), "Fostering Cross Cultural Competence in Preservice Teachers Through Multicultural Education Experiences", Early Childhood Education, No. 38, pp. 197-204. DOI: 10.1007/s10643-010-0401-5

Keengwe, J. (2007), "Cultural diversity: Empowering teacher educators with cultural and linguistic tools to support diverse learners in the classroom", The Ohio Journal of Teacher Education, Vol. 20 No. 1, pp. 17-22.

Moll, L.C., Arnot-Hopffer, E. (2005), "Sociocultural competence in teacher education", Journal of Teacher Education, Vol. 56 No. 3, pp. 242-247. DOI: 10.1177/00224871052 75919

Murray, R.B., Mount, K.M. (1991), “The Big Five Personality Dimensions and job performance: a meta analysis", Personnel Psychology, No. 44, pp. 1-26.

Panikkar, K.N., Nair, B.M. (2012), Globalization and higher education in India, Pearson, India.

Project Atlas (2013), available at: www.iie.org/en/Services/Project-Atlas/India/IndiasStudents-Overseas (accessed 20 May 2017).

Rajput, J.S., Walia, K. (2001), "Reforms in teacher education in India”, Journal of Educational Change, No. 2, pp. 239-256.

Rowley, J. (2003), "Designing student feedback questionnaires", Quality Assurance in Education, Vol. 11 No. 3, pp. 142-149. DOI: 10.1108/09684880310488454

Sadker, M., Sadker, D., Zittleman, K. (2008), Teachers, schools, and society, McGrawHill, New York.

Santoro, N., Kennedy, A. (2015), "How is cultural diversity positioned in teacher professional standards? An international analysis", Asia-Pacific Journal of Teacher Education, Vol. 44 No. 3, DOI: http://dx.doi.org/10.1080/1359866X.2015.1081674

Stakhiv, M., Boiko, H. (2017), “Sociocultural Component of Teachers' Professional 
A QUALITATIVE STUDY OF STUDENTS' PERCEPTION

Kamila Ludwikowska
Competence", Journal of Vasyl Stefanyk Precarpathian National University, Vol. 4 No. 1, pp. 110-116. DOI: 10.15330/jpnu.4.1.110-116

Sue, D.W., Bernier, J.E., Durran, A., Feinberg, L., Pedersen, P., Smith, E.J., VasquezNuttall, E. (1982), "Position paper: cross-cultural counseling competencies", The Counseling Psychologist, Vol. 10 No. 2, pp. 45-52. DOI: 10.1177/0011000082102008

Vélez, A.P, Olivencia, J.J.L. (2017), "Attitudes and perceptions towards cultural diversity and interculturality in the university context. A comparative study", Procedia-Social and Behavioral Sciences, Vol. 237, pp. 548-553. DOI: 10.1016/j.sbspro.2017.02.105 